\title{
Studies on Pathophysiological Effects of Postalimentary \\ Lipemia in Patients with Ischemic Heart Disease
}

\author{
Hisashi Fukuzaki, Ryozo Okamoto, \\ AND TAKEFUMI MATSUO
}

$\mathbf{H}$

YPERLIPIDEMIA has been highly evaluated as one of the coronary risk factors! Ischemic heart disease is understood pathophysiologically to be the hypoxic state of heart muscle induced by the reduction of coronary blood flow resulting from the coronary atherosclerosis.

The purpose of the present studies is to elucidate the pathophysiological significance of the postalimentary lipemia induced by the intake of a great deal of animal fat in patients with ischemic heart disease. Observations were made of the effects of postalimentary lipemia (PAL) on electrocardiograms, blood gases and hematological properities in patients with ischemic heart disease (IHD).

\section{Methods and Results}

To produce the PAL in patients with IHD and in normal subjects, the fat intake was carried out as follows.

They were fasted for 12 hours (hr) prior to the test and then the raw cream which contained $25 \%$ fat was given orally in a dosage of $200 \mathrm{~g}$ in the hematological observations and $100 \mathrm{~g}$ in the other observations. To induce the clearing of PAL, heparin was administered intravenously at a dose level of $40 \mathrm{U} / \mathrm{Kg}$ body weight. The levels of PAL were indicated by the optical densities of the plasma diluted $1: 6$ with water measured at

Key Words:

Postalimentary lipemia

Pathophy siology of IHD

Ischemic change in $\mathrm{ECG}$

Blood gases

Hematological properties the wave length $650 \mathrm{~m} \mu$ with spectrophotometer. 1) Statistical observation was made of the inducing factors of myocardial infarction in 208 patients (Table I). The number of patients in whom the attack of myocardial infarction occurred after meals were 30 cases, $14.4 \%$ of total subjects.

2) Observation of electrocardiogram (ECG)

Electrocardiographic patterns in twelve leads before and 2, 4 and $6 \mathrm{hr}$ after fat intake were observed in 50 patients with IHD and 33 normal subjects (Table II). The incidence of ischemic change in ECG after fat intake was much higher in patients with IHD than in normal subjects. Especially it was noted that $61 \%$ of 18 cases with angina pectoris (11 cases) revealed ST depression after fat intake. It was also demonstrated that the ischemic change in ECG appeared most frequently 4 or $6 \mathrm{hr}$ after fat intake when the level of PAL reaches its maximum value.

Based on these findings, it is postulated that myocardial hypoxia is promoted by PAL in patients with IHD. The mechanism of this

TABLE I SITUATION OF ONSET OF ACUTE MYOCARDIAL INFARCTION

\begin{tabular}{lcc}
\hline \hline Sleeping & 41 & $(19.7)$ \\
At awakening & 12 & $(7.8)$ \\
At lavatory & 14 & $(6.7)$ \\
After meal & 30 & $(14.4)$ \\
Physical exercise & 45 & $(21.6)$ \\
Mental stress & 12 & $(5.8)$ \\
Others & 21 & $(10.1)$ \\
Unknown & 29 & $(13.9)$ \\
Total cases & 208 & $(\%)$ \\
\hline
\end{tabular}

Department of Internal Medicine, Division I, Kobe University School of Medicine, Kobe

* Gist of this paper was presented at Symposium on "Circulatory Disease and Hyperlipidemias" at the 38th Annual Meeting of the Japanese Circulation Socie ty in Yamaguchi, April 7, 1974. 
TABLE II CHANGES IN ECG AFTER ORAL F AT INTAKE IN CONTROLS AND PATIENTS WITH IHD

\begin{tabular}{|c|c|c|c|c|}
\hline $\begin{array}{l}\text { Change in electro- } \\
\text { cardiographic pattern }\end{array}$ & $\begin{array}{l}\text { ST elevation } \\
\quad>1 \mathrm{~mm}\end{array}$ & $\begin{array}{l}\text { ST depression } \\
>1 \mathrm{~mm}\end{array}$ & $\begin{array}{c}\text { Increase of } \\
\text { T-ampl. } \\
>2 \mathrm{~mm}\end{array}$ & $\begin{array}{c}\text { Decrease of } \\
\text { T-ampl. } \\
>2 \mathrm{~mm}\end{array}$ \\
\hline Young Controls (17) & 5 & 2 & 6 & 6 \\
\hline Aged Controls (16) & 2 & 5 & 4 & 6 \\
\hline Myocardial infarction (7) & 1 & 2 & 0 & 3 \\
\hline Angina pectoris (18) & 4 & 11 & 3 & 10 \\
\hline IHD without Pain (25) & 5 & 9 & 8 & 12 \\
\hline
\end{tabular}

TABLE III CHANGES IN A-V DIFFERENCE OF Po $\mathrm{P}_{2}$ FOLLOWING HEPARIN INJECTION IN FASTING STATE AND AFTER FAT INTAKE

\begin{tabular}{lcccccc}
\hline & $\begin{array}{c}\text { Before } \\
\text { heparin }\end{array}$ & $5^{\prime}$ & $15^{\prime}$ & $30^{\prime}$ & $45^{\prime}$ & $60^{\prime}$ \\
\hline $\begin{array}{c}\text { Fat intake } \\
(\mathrm{mmHg})\end{array}$ & $23.6 \pm 3.2$ & $-3.5 \pm 3.9$ & $+0.7 \pm 3.6$ & $+2.6 \pm 3.3$ & $-2.5 \pm 2.4$ & $+0.5 \pm 3.1$ \\
\hline $\begin{array}{l}\text { Fasting } \\
(\mathrm{mmHg})\end{array}$ & $29.9 \pm 2.2$ & $-7.8 \pm 2.1$ & $-2.4 \pm 2.2$ & $-6.9 \pm 2.6$ & $-8.3 \pm 3.6$ & $-3.3 \pm 3.4$ \\
\hline
\end{tabular}

phenomenon was investigated in special reference to the effects of PAL on blood gases and hematological properties.

3) Observations of blood gases

(1) Arterial oxygen tension $\left(\mathrm{PaO}_{2}\right):$ In 10 patients with IHD, heparin was injected intravenously $4 \mathrm{hr}$ after fat intake. Blood samples were taken from the brachial artery before and 2 and $4 \mathrm{hr}$ after fat intake and $30 \mathrm{~min}$ after the injection of heparin. Determinations of $\mathrm{PaO}_{2}$ and $\mathrm{PaCO}_{2}$ of these samples were carried out by means of IL meter to which the principle of polarography was applied.

$\mathrm{PaO}_{2}$ was lowered 2 and $4 \mathrm{hr}$ after fat intake and then returned to almost the initial value 30 min after the injection of heparin (Fig. 1). The degree of the lowering of $\mathrm{PaO}_{2} 4 \mathrm{hr}$ after fat intake and that of the elevation of $\mathrm{PaO}_{2} 30 \mathrm{~min}$ after the injection of heparin were statistically significant $(\mathrm{P}<0.01)$, whereas no significant change in $\mathrm{PaCO}_{2}$ was found after these procedures.

(2) Arterio-venous difference of oxygen tension in the forearm (Table III): In 15 patients with IHD, heparin was injected intravenously 4 hr after fat intake, and before and 5, 15, 30,
45 and 60 min after the injection, blood samples were obtained concurrently from the brachial artery and the deep median vein. Of these samples determinations of $\mathrm{Po}_{2}$ were carried out and the change in arterio-venous difference of oxygen tension $\left(\mathrm{P}(\mathrm{a}-\mathrm{v}) \mathrm{O}_{2}\right)$ in the forearm was observed. In addition, the observation was made of $\mathrm{P}(\mathrm{a}-\mathrm{v}) \mathrm{O}_{2}$ after the injection of heparin in the fasting state of 10 patients with IHD.

In the fasting state, a decrease of $\mathrm{P}(\mathrm{a}-\mathrm{v}) \mathrm{O}_{2}$ was found at each period after the injection of heparin. In the lipemic state, on the contrary, a slight increase of $\mathrm{P}(\mathrm{a}-\mathrm{v}) \mathrm{O}_{2}$ was found 15 and 30 min after the injection of heparin when the most pronounced clearing of PAL occurred.

4) Changes in hematological properties

(1) Coagulability and platelet adhesiveness: in 14 patients with IHD and 10 normal subjects, plasma recalcification time, plasma prothrombin time and platelet adhesiveness were measured before and 1,2 and $4 \mathrm{hr}$ after fat intake. Method used in the determination of recalcification time and that of prothrombin time were the same as that described by Stefanini ${ }^{2}$ and by Quick, respectively. The method of the determination of platelet adhesiveness has been described else- 


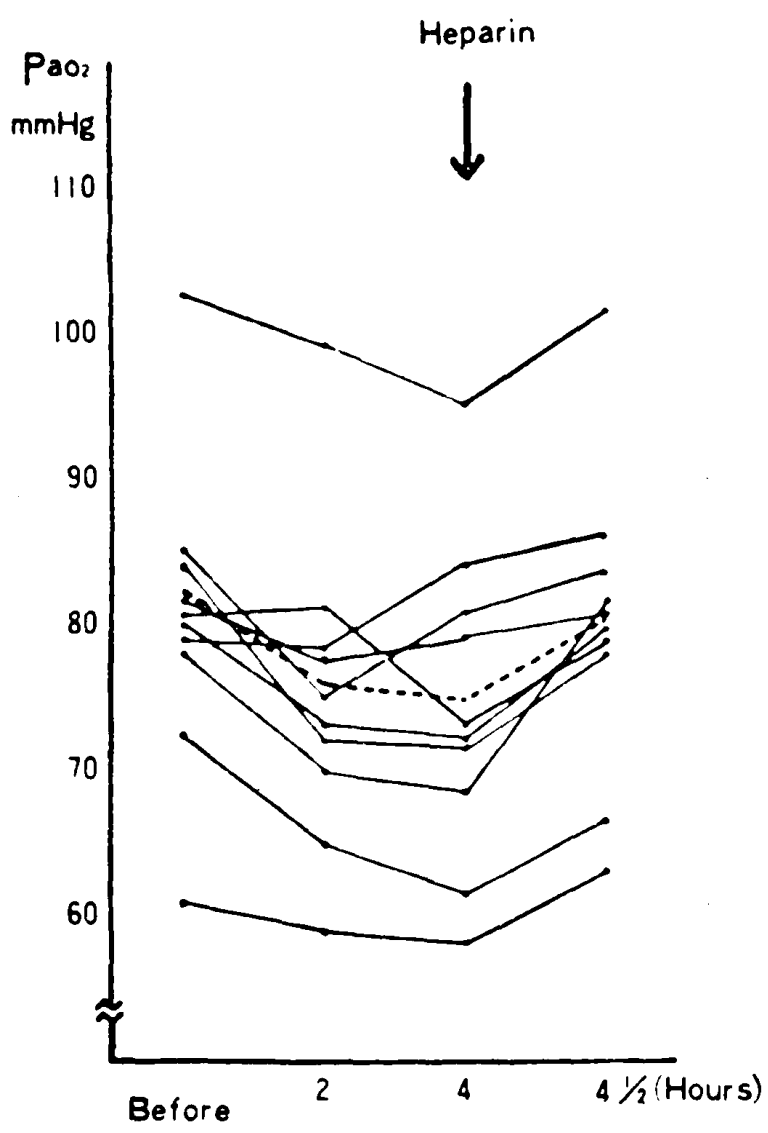

Fig.1. Changes in $\mathrm{Pao}_{2}$ after oral fat intake and subsequent heparin injection.

where. The change of plasma recalcification time in normal subjects indicated a prolongation $1 \mathrm{hr}$ after fat intake with a subsequent shortening. In patients with IHD, only a trend of shortening of plasma recalcification time was found in the absence of the phase of prolongation. The change of plasma prothrombin time in normal subjects and in patients with IHD was almost the same as that of plasma recalcification time, respectively (Fig. 2). The change of platelet adhesiveness after fat intake was observed in comparison with that of plasma optical density (OD). After fat intake a more marked increase in platelet adhesiveness was found in patients with IHD than in normal subjects. In parallel with this finding, it was revealed that an elevation of plasma OD after fat intake in the former was more pronounced than that in the latter (Fig. 3). Further observation was made of the patterns of platelet adhesiveness following fat intake, and they were divided into several types. In patients with IHD, type III which indicated the most pronounced increase in platelet adhesiveness after fat intake compared with other types exhibited the greatest increment in plasma OD as well (Fig. 4). These results apparently indicate that both blood coagulability and platelet adhesiveness are accelerated by PAL in patients with IHD.

(2) Effect of fat on red blood cells: In 6 normal subjects, venous blood was taken prior to and $4 \mathrm{hr}$ after fat intake and each sample was divided into plasma and red blood cells $(\mathrm{RBC})$ by centrifugation. The lipemic plasma was mixed with the fasting $\mathrm{RBC}$ and incubated at $37^{\circ} \mathrm{C}$ for $30 \mathrm{~min}$ and then the plasma was separated again. The values of OD of both lipemic plasma before and after the treatment with $\mathrm{RBC}$ were compared. A singnificant decrement $(\mathrm{p}<0.005)$ of plasma OD was demonstrated by the treatment with the RBC (Fig. 5). Whatever may be the mode of action, it is apparent that chylomicrons in the lipemic plasma are uptaken by the RBC. Accordingly, further observation was made of this problem.

The admixture of the fasting plasma of normal subjects and the sesame oil emulsion (Fatgen*) was incubated at $37^{\circ} \mathrm{C}$ for $30 \mathrm{~min}$. After this pretreatment, the fasting RBC were added to the admixture and incubated again at $37^{\circ} \mathrm{C}$ for $30 \mathrm{~min}$. Then the blood smear preparation was made and stained with SudanBlack B. Microscopical examination revealed that fat granules were adsorbed on the surface of RBC and that $\mathrm{RBC}$ were agglutinated together through somewhat greater fat granules (Fig. 6,7).

5) Preventive measures against the pathophysiological effect of PAL

(1) Low molecular dextran sulfate (LMDS): In 12 patients with IHD, $300 \mathrm{mg}$ of LMDS** was injected intravenously $4 \mathrm{hr}$ after fat intake and observations were made of the changes in hematological properties after the injection.

A decrease in platelet adhesiveness and a prolongation of both plasma recalcification time and plasma prothrombin time were demonstrated after the treatment with LMDS in parallet with a lowering of plasma OD (Fig. 8). From these results, a favourable effect of LMDS on PAL is suggested, however its clinical use in patients with IHD is still controversial as discussed later.

(2) Intravenous injection of glucose: In 5 normal subjects and 9 patients with atherosclerosis, $20 \mathrm{ml}$ of $50 \%$ glucose solution was injected intravenously $3 \mathrm{hr}$ after fat intake and its effect on plasma OD was observed. A

\footnotetext{
* supplied by DAI NIPPON SEIYAKU COMPANY

** supplied by KOWA SHINYAKU COMPANY
} 
Recalcification Time Prothrombin Time
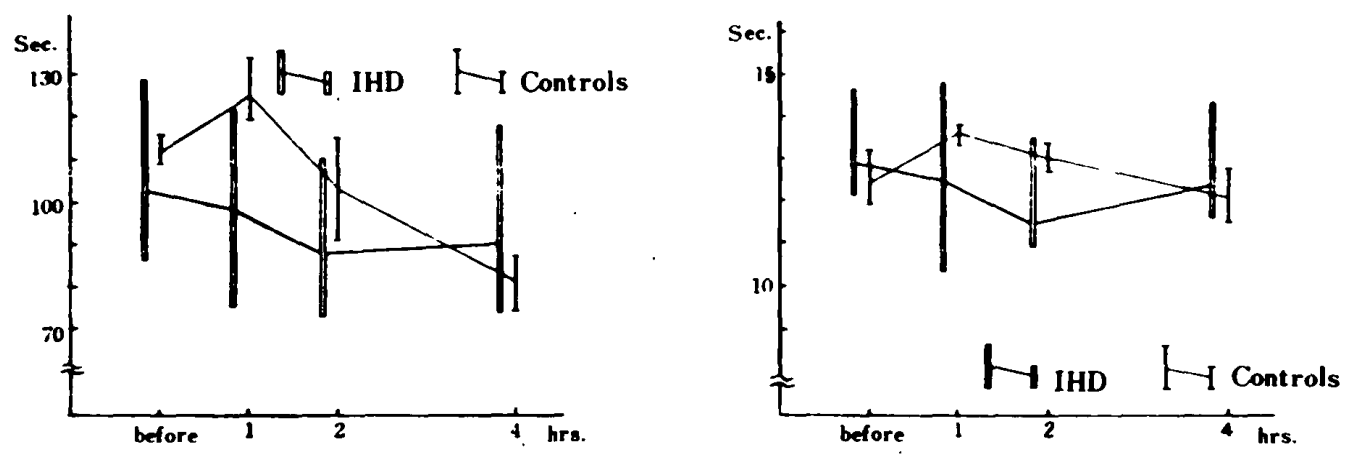

Fig.2. Changes in blood coagulability after fat intake in controls and patients with IHD.

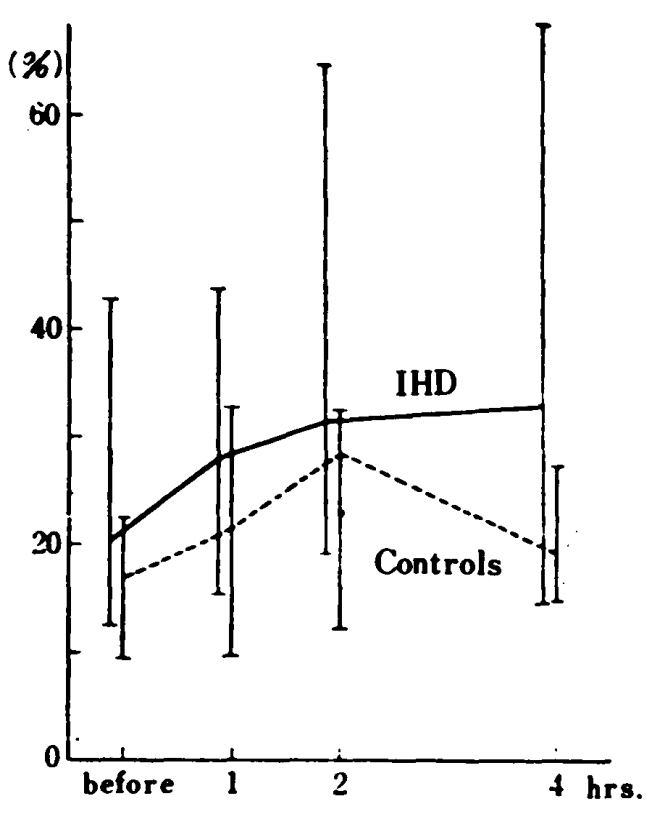

Platelet Adhesiveness

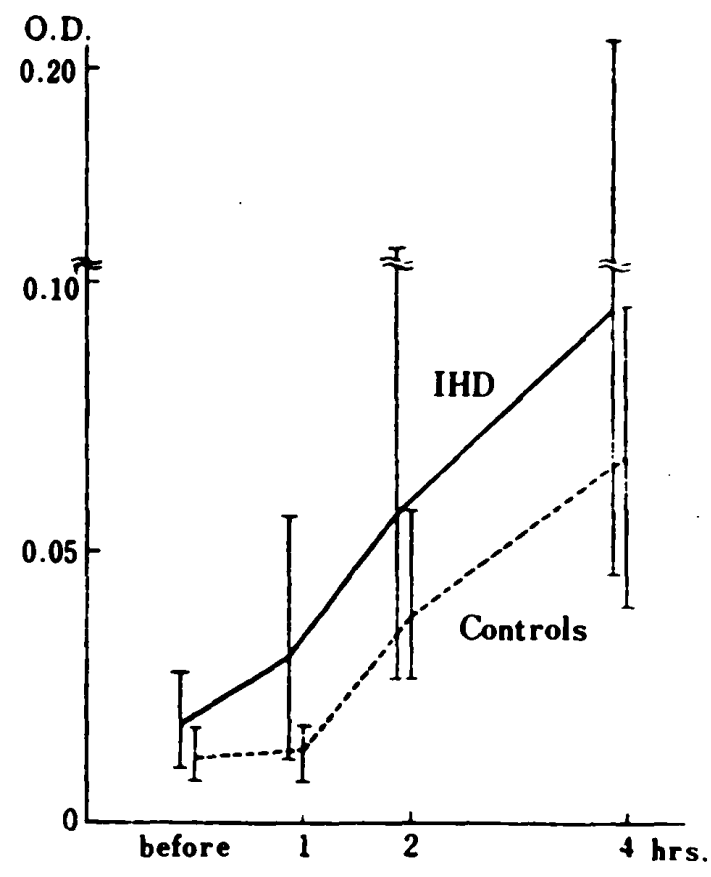

O. D.

Fig.3. Changes in platelet adhesiveness and O.D. after fat intake.

significant lowering of OD after the injection of glucose was found in both groups $(P<0.05)$, although it was less pronounced in the patients group than in the normal group (Fig. 9).

\section{Discussion}

A concept regarding the coronary risk factors has been brought forward mainly on the basis of epidemiological and clinical statistics. The pathophysiological mechanisms which underlie these factors still remain obscure. Excessive intake of animal fat has been appreciated as an important risk factor to promote the development of coronary atherosclerosis. The present studies were attempted to elucidate the pathophysiological significance of postalimentary lipemia (PAL) induced by the intake of raw cream in patients with IHD.

Our findings of the changes in ECG after fat intake in patients with IHD are essentially in accord with those of Kuo and his associates ${ }^{5,6}$ although no anginal attack was demonstrated in our subjects. Based on the fact that the appearance of ischemic change of ECG after fat intake coincides with the arrival of plasma OD at its maximum value, it is suggested that there is a 

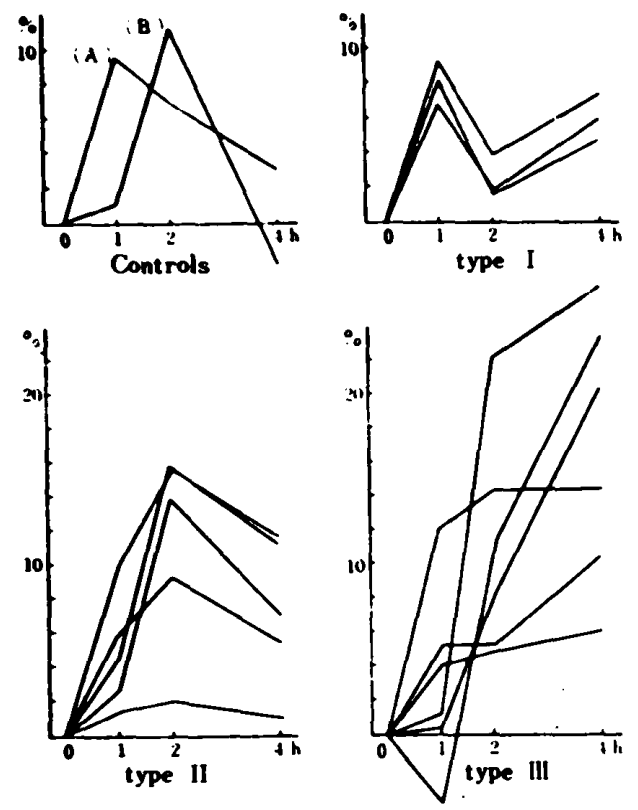

Platelet Adhesiveness

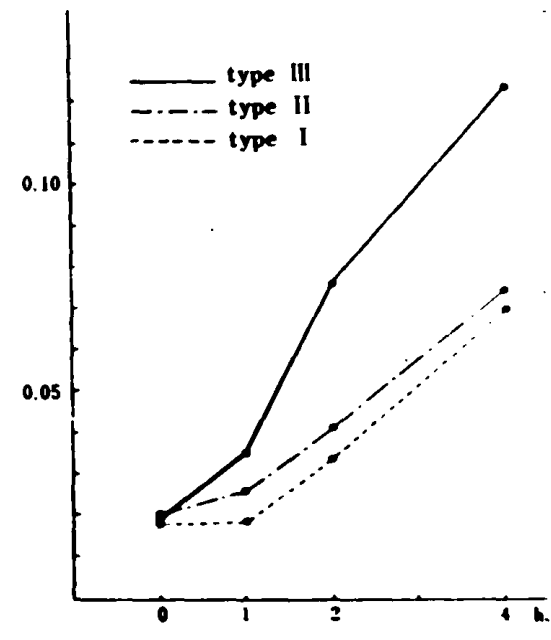

O. D.

Fig.4. Types of the changes in platelet adhesiveness after fat intake and the relationship with the patterns of O.D.

close relation between PAL and myocardial ischemia. It is of interest, in addition, that our statistical survey revealed a considerably high incidence of acute myocardial infarction after meals. These results indicate that PAL may exert a deleterious effect on the myocardium in patients with IHD whose coronary blood flow have already been reduced by coronary atherosclerosis. Further studies were made on the pathophysiological mechanism which underlay the development of lipemia-induced myocardial hypoxia in patients with IHD.

A marked reduction of $\mathrm{PaO}_{2}$ after fat intake is considered to be due to the disturbance of pulmonary function. Although the mechanisms involved in this process remain to be determined, hypoventilation is eliminated because of no significan change in $\mathrm{Pa}_{\mathrm{CO}_{2}}$ after fat intake.

In our observation, the arterio-venous difference of oxygen tension in the forearm under the condition of PAL was increased after the intravenous injection of heparin although under the fasting condition it was decreased after the administration of heparin. Therefore, it is postulated that in the lipemic state after fat intake, heparin though it may have some augmentative action on peripheral blood flow induces a marked clearing of PAL and consequently an increase of oxygen uptake by peripheral tissues. It seems, thus, likely that the oxygen supply to peripheral tissues is impaired by PAL probably due to the disturbance of oxygen diffusion. However, further works which direct toward determining the effects of PAL on both blood flow and metabolic process in peripheral tissues are needed. Our concept mentioned above is essentially similar to that of Engelberg, ${ }^{7,8}$ Regan, $^{9} K^{1} o^{10}$ and Joyner, ${ }^{1}$ although there are some differences between our and their methods of observations.

Whatever may be the mode of action, it is apparent that PAL interferes with both pulmonary function and oxygen uptake by peripheral tissues and then results in the development of myocardial hypoxia in patients with IHD.

A considerable amount of research has been reported on the augmentative effect of PAL on blood coagulability 12,13,14 In the present studies, the acceleration of platelet adhesiveness as well as that of blood coagulability was demonstrated after fat intake. These alterations of hematological properties are regarded as the contributory factors to the development of thrombosis.

Observations were made of the effect of plasma chylomicrons on red blood cells (RBC) and it was suggested taht the agglutinatio of $\mathrm{RBC}$ occurred as a result of fat adsorption on the membrane of RBC in the state of PAL. These results support the views of Swank, ${ }^{15}$ Williams ${ }^{16}$ 


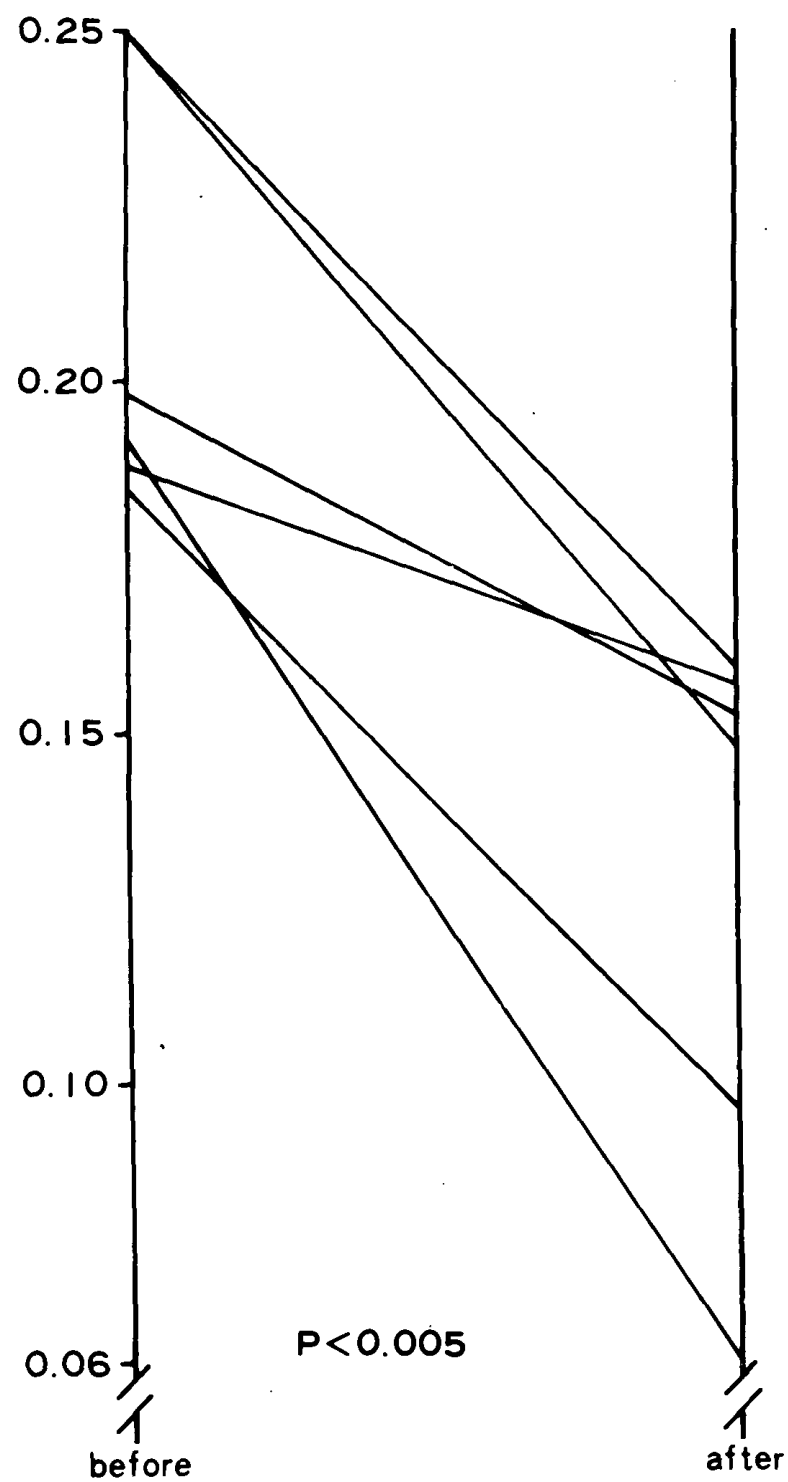

Symposium I Circulatory Diseases and Hyperlipidemias

and $B s c h r^{1} 7$ that the disturbance of peripheral circulation is induced by high fat intake and it is ascribed to the sludge phenomenon of blood.

It is, thus, highly possible that oxygen supply to the heart muscle in patients with IHD is reduced after high fat meal through the impaired coronary circulation due to the changes in hematological properties.

On the basis of the results of present studies with regard to the lipemia-induced changes in blood gases and hematological properties, it is evident that PAL exert a deleterious effect on oxygen supply to the myocardium in patients with IHD.

As to the preventive measures against the unfavourable effects of PAL in patients with IHD, it was suggested that a concurrent intake of carbohydrate might be of clinical use. As an available evidence, it was revealed that the intravenous injection of glucose could accelerate the removal of chylomicrons from the blood stream by promoting the removal of plasma FFA, the product of lipolysis. Therefore, in patients with IHD the disturbance of carbohydrate metabolism, if any, should be improved beforehand. Despite of having a strong clearing action of PAL, neither heparin nor low molecular dextran sulfate is recommended as an appropriate preventive measure, because the treatment with either substance results in a considerable elevation of plasma content of FFA and consequently may develop the serious arrhythmia in patients with IHD! 8

\section{SUMMARY}

The present studies were undertaken to

Fig.5. Changes in O.D. of lipemic plasma after mixing with red cells obtained from fasting blood.

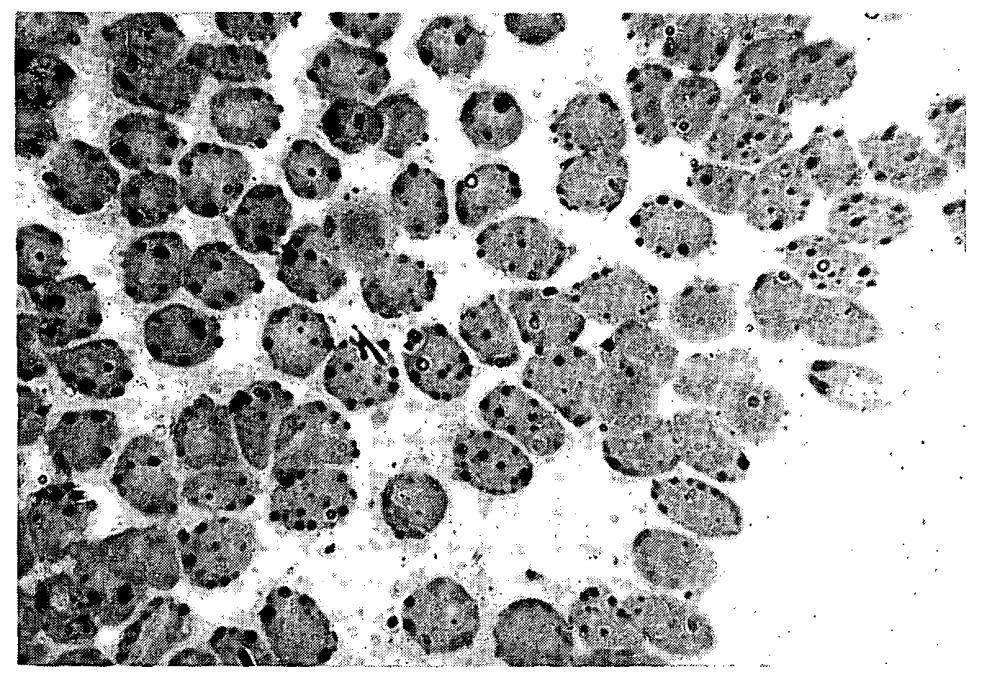

Fig.6. Fat granules are adsorbed on the surface of red blood cells. 


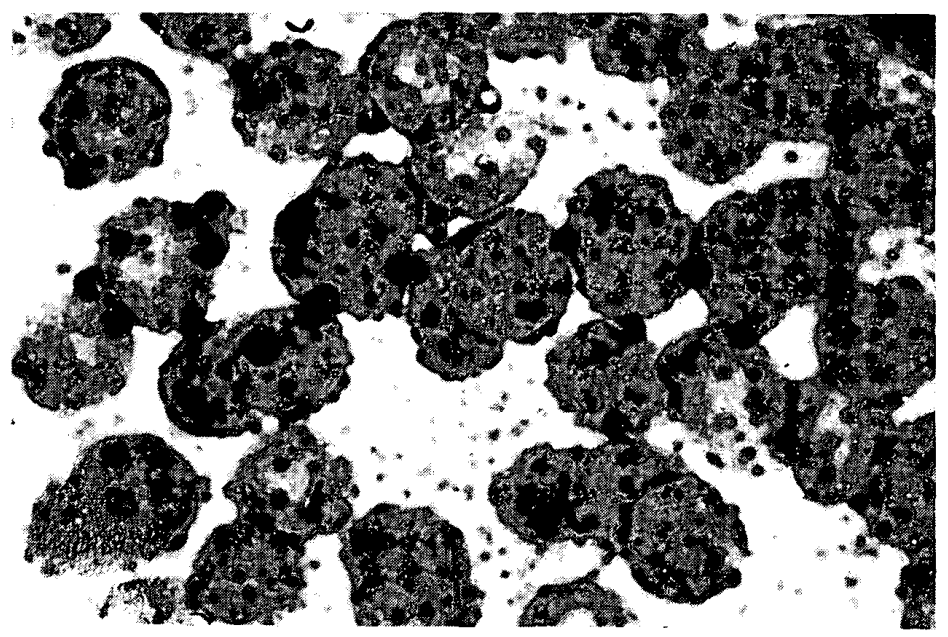

Fig.7. Suggestive finding of the red blood cell agglutination through large fat granules is shown.

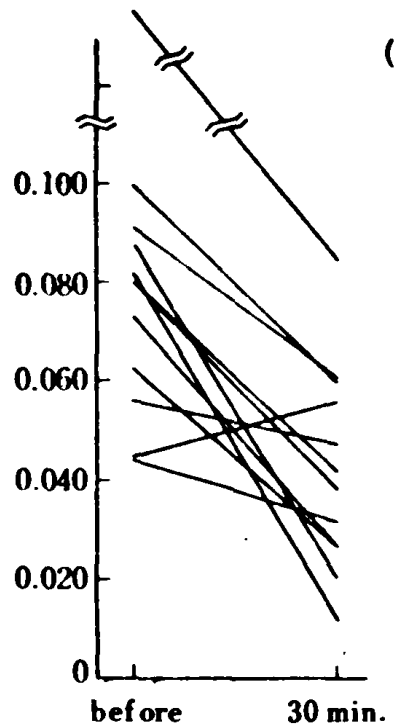

O. D.

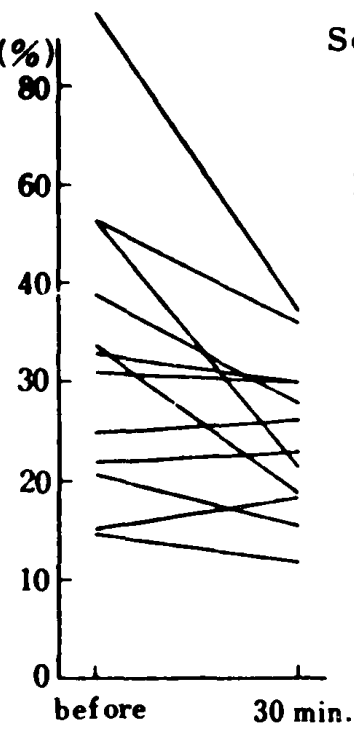

PL-Adh.

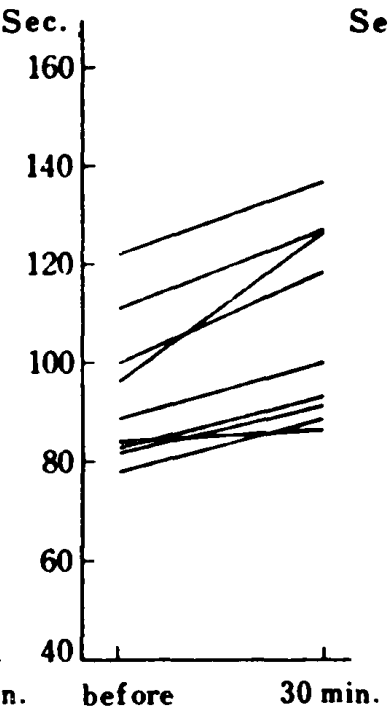

Recalc.

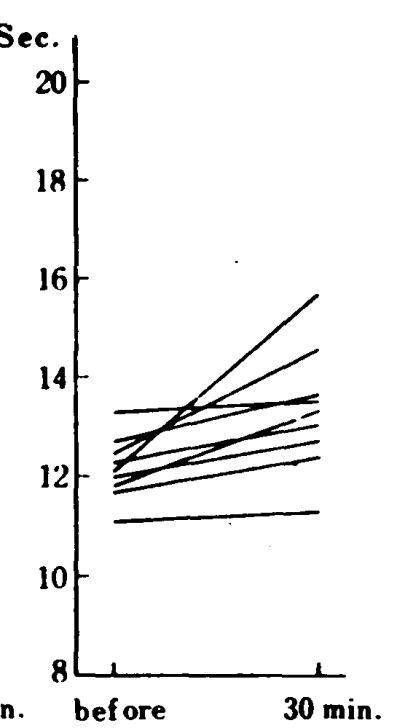

Prothr.

Fig.8. Effects of i.v. injection of dextran sulfate on O.D., platelet adhesiveness and coagulability after fat intake in patients with IHD.

elucidate the pathophysiological effects of postalimentary lipemia(PAL) induced by the intake of much animal fat in patients with ischemic heart disease(IHD) and the preventive measures against them.

Results obtained were as follows: 1) Occurrence or augmentation of ischemic changes in ECG was demonstrated after fat intake. 2) After fat intake, lowering of arterial oxygen tension and heparin-induced increase in arterio-venous difference of oxygen tension in the forearm were observed. 3) PAL resulted in an acceleration of platelet. adhesiveness as well as a shortening of plasma recalcification time and that of plasma prothrombin time. 4) It was revealed that red blood cells adsorbed fat on their membrane and then readily agglutinate together. 5) Removal of chylomicrons from the blood stream was accelerated by the intravenous injection of glucose.

These results lead to the following conclusions:

1) PAL exerts a deleterious effect on the oxygen supply to the myocardium in patients with IHD and it is probably due to the disturbance of pulmonary function and that of oxygen diffusion and blood flow in the myocardium.

2) As one of preventive measures against the the concurrent intake of carbohydrate in an appropriate quantity appears to be of use. 

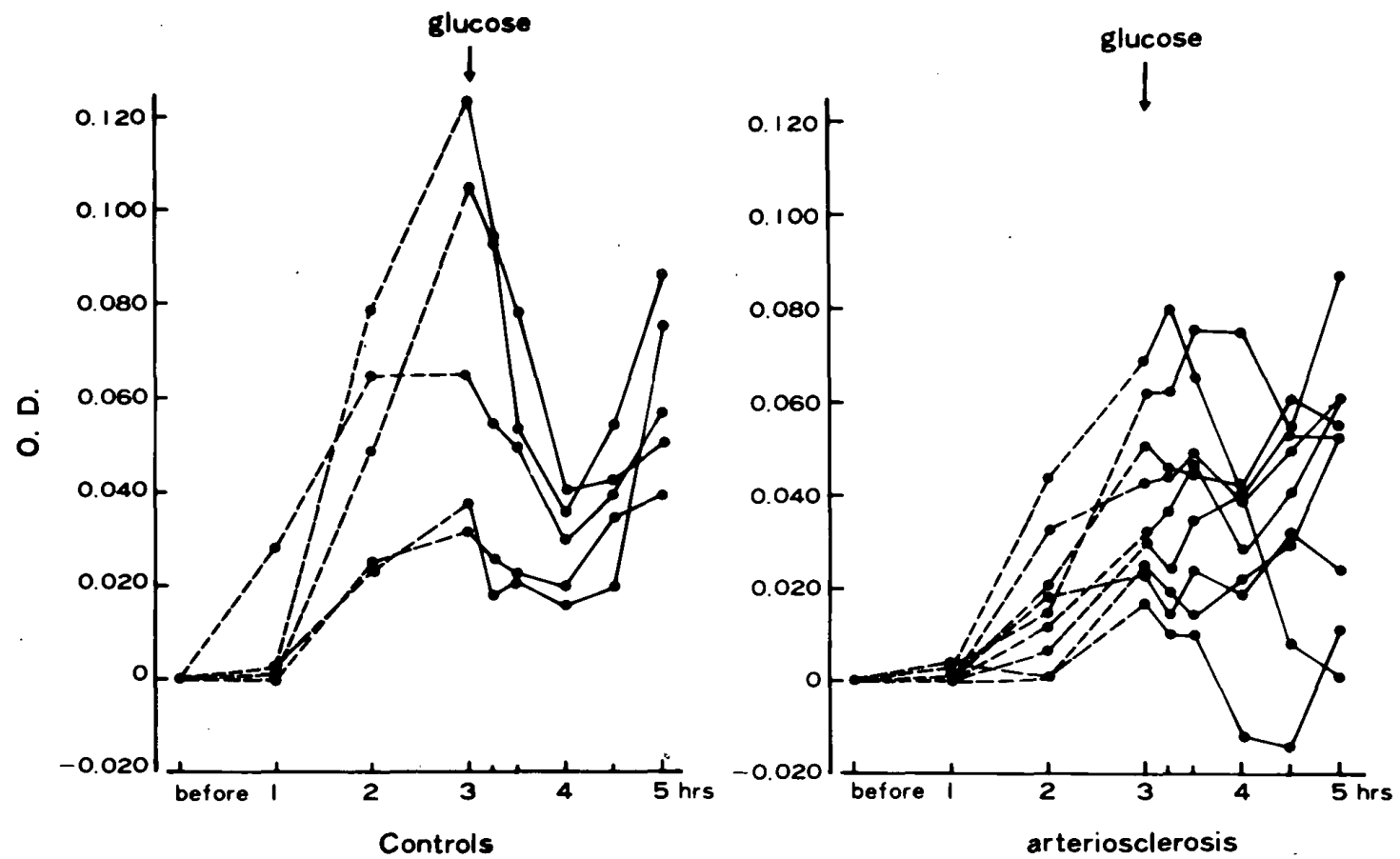

Fig.9. Effect of glucose injection on changes in plasma O.D. after oral fat intake in controls and patients with arteriosclerosis.

\section{REFERENCES}

1. KANNEL, W. B., DAWBER, T. P., KAGAN, A., REVOTSKIE, N., \& STOKES, J., III: Factors of risk in the development of coronary heart disease, six-year follow-up experience, The Framingham study. Ann. Intern. Med. 55: 33, 1961.

2. STEFANINI, M. \& DAMESHEK, W.: The Hemorrhagic Disorders, 2nd ed., Gune \& Stratton, p. 477, 1962.

3. QUICK, A. J., STANLEY, B. M. \& BANCROFT, F. W.: Study of the coagulation defect in hemophilia and jaundice. Am. J. Med. Sci. 190: $501,1935$.

4. IMAMURA, H., FUKUZAKI, H., TAKAMIYA, T. \& MATSUO, T.: Postalimentary lipemia and platelet adhesiveness in patients with coronary atherosclerosis. Naika 29: 123, 1972. (in Japanese)

5. KUO, P. T. and JOYNER, C. R., Jr.: Angina pectoris induced by fat ingestion in patients with coronary artery disease: Ballistocardiographic and electrocardiographic findings. $J . A . M . A$. 158: $1008,1955$.

6. KUO, P. T. \& JOYNER, C. R., Jr.: Effect of heparin on lipemia-induced angina pectoris. J.A. M. A. 163: 727, 1957.

7. ENGELBERG, H. \& KUHN, R.: Studies of forearm arterio-venous oxygen differences in atherosclerotic patients before and after heparin. Angio$\log y$ 7: 73, 1956.

8. ENGELBERG, H.: The effect of heparin upon the total oxygen consumption of atherosclerotic individuals. Am. J. Med. Sci. 236: 175, 1958.

9. REGAN, T. J., BINAK, K., GORDON, S., DEFAZIO, V., \& HELLEMS, H. K.: Myocardial blood flow and oxygen consumption during post- prandial lipemia and heparin-induced lipolysis. Circulation 23: 55, 1961.

10. KUO, P. T., WHEREAT, A. F. \& HORWITZ, O.: The effect of lipemia upon coronary and peripheral arterial circulation in patients with essential hyperlipemia. Am. J. Med. 26: 68, 1959.

11. JOYNER, C. R. Jr., HORWITZ, O. \& WILLIAMS, P. G.: The effect of lipemia upon tissue oxygen tension in man. Circulation 22: 901, 1960.

12. SCHMIDT, J. \& CLIFFORD, G. O.: A sensitive test for the detection of coagulation abnormalities in hyperlipemia. J. Clin. Invest. 39: 1026, 1960.

13. ROTH, H. C., ROSENTHAL, W. \& MANDEL, E. E.: Lipemia-induced acceleration of intravascular clotting. Proc. Soc. Exptl. Biol. and Med. 101: 516, 1959.

14. DUBBER, A. H. C., RIFKIND, B., GALE, M., McNICOL, G. P. \& DOUGLAS, A. S.: The effect of fat feeding on fibrinolysis 'Stypven' time and platelet aggregation. J. Atheroscler. Res. 7: $225,1967$.

15. SWANK, R. L.: Changes in blood of dogs and rabbits by high fat intake. Am. J. Physiol. 196: 473, 1959.

16. Williams, A. V., HIGGinbothAM, A. C., MELVIN, $M$. and KNISELY, M. H.: Increased blood cell agglutination following ingestion of fat. A factor contributing to cardiac ischemia, coronary insufficiency and anginal pain. A contribution to the biophysics of disease. Angiology 8: 1, 1957.

17. BSCHOR, F. \& DEININGER, R.: Einfluss der Hyperlipaemie auf die Thrombogenese im Coronarsystem des isolierten Katzenherzens. Klin. Wschr. 42: 435, 1964.

18. KURIEN, V. A. and OLIVER, M. F.: Free fatty acids during acute myocardial infarction. Prog. Cardiovasc. Dis. 13: 361, 1971. 